\title{
GESTÃO DE SERVIÇOS DE ENGENHARIA EM UNIVERSIDADES PÚBLICAS FEDERAIS DO NORDESTE BRASILEIRO: Um estudo para contratações públicas sustentáveis
}

\author{
José Luiz Alves \\ Doutor em Geografia \\ Professor do Programa de Pós-Graduação em Gestão do Desenvolvimento Local Sustentável \\ Universidade de Pernambuco \\ luiz.alves@upe.br
}

Egbert Walmeron Duarte Costa

Mestrando em Gestão do Desenvolvimento Local Sustentável Programa de Pós-Graduação em Gestão do Desenvolvimento Local Sustentável Universidade de Pernambuco egbertcosta@yahoo.com.br

\section{Resumo}

Motivado a contribuir para a consolidação das licitações sustentáveis na administração pública alinhadas ao desenvolvimento sustentável e à imposição legal, este artigo pesquisou critérios para redução do consumo de energia elétrica em processos licitatórios de obras de engenharia utilizados por universidades públicas federais do nordeste brasileiro no tocante às contratações públicas sustentáveis. A metodologia utilizada foi a teórica e aplicada quanto à natureza, exploratória e descritiva quanto ao objetivo, e bibliográfica e documental quanto aos procedimentos. As fontes para coleta de dados foram o portal de compras do governo federal (Comprasnet) e uma pesquisa bibliográfica e documental que envolveu os Planos de Gestão de Logística Sustentável das universidades estudadas. A abordagem da pesquisa é quali-quanti porque envolveu tratamento de dados com base em categorias definidas previamente, bem como coleta de dados segundo parâmetros previamente estabelecidos. As considerações finais mostram que as universidades estudadas precisam superar alguns obstáculos, tais como pouca capacitação dos gestores públicos e cultura organizacional para que suas contratações públicas sustentáveis se tornem políticas públicas eficazes alinhadas ao desenvolvimento sustentável.

\section{Palavras-chave}

Contratações públicas sustentáveis. Desenvolvimento sustentável. Universidades públicas federais do nordeste brasileiro. Políticas públicas. Obras de engenharia.

\section{INTRODUÇÃO}

Licitações Sustentáveis (LS) são dadas como "aquelas que levam em consideração a sustentabilidade ambiental, social e econômica dos produtos e processos a ela relativos", conforme o $5^{\circ}$ e $6^{\circ}$ eixos da Agenda Ambiental na Administração Pública (A3P) (BRASIL, 2009), bem como aquelas que visam diminuir os impactos sobre o meio ambiente a favor dos direitos humanos (CARVALHO; FERREIRA; VILLAC, 2016, p. 12).
O processo de Contratação Pública Sustentável (CPS) está em coerência aos preceitos da Agenda 21 global quando afirma, em seu capítulo 4, que "as principais causas da deterioração ininterrupta do meio ambiente mundial são os padrões insustentáveis de consumo e produção". Adiante, o mesmo documento reforça a necessidade de que todos os países devem atuar no sentido de promover padrões de consumo sustentáveis (CONFERÊNCIA DAS NAÇÕES UNIDAS SOBRE MEIO AMBIENTE E DESENVOLVIMENTO, 1996). 
As CPS também se inserem dentro do contexto dos Objetivos do Desenvolvimento Sustentável (ODS) instituídos pela Agenda 2030 que contempla 169 metas distribuídas em 17 objetivos. Alinhado diretamente ao tema deste trabalho está o objetivo $\mathrm{n}^{\circ} 7$ (ORGANIZAÇÃO DAS NAÇÕES UNIDAS, 2015).

Aqui faz-se necessário pontuarmos que a Administração Pública consome produtos e serviços durante a gestão de suas atividades de engenharia, através de contratos feitos via processo licitatório, conforme inciso XXI do artigo 37 da Constituição Federal (BRASIL, 1988), quando afirma que obras, serviços e compras serão contratados mediante processo de licitação pública.

A obrigatoriedade de realizar licitações é citada por Di Pietro (2016, p. 415), quando a autora faz referência ao fato de que a licitação é ato vinculado, pois se trata de obediência ao princípio da indisponibilidade do interesse público que se constitui de uma "restrição à liberdade administrativa na escolha do contratante", ou seja o contratante deverá ser escolhido conforme as melhores condições ao interesse público e não apenas pelo menor preço ofertado.

Bliacheris (2015) relata que as LS são institucionalizadas e introduzidas no ordenamento jurídico brasileiro porque se constituem como políticas públicas que devem ser promovidas pela administração pública (ROSSET, 2017) através de suas contratações públicas as quais representam aproximadamente $10 \%$ a $15 \%$ do PIB nacional (BRASIL, 2009). Nesse sentido, a administração pública pode viabilizar obras e serviços de engenharia para materializar tais políticas, conforme Pereira Júnior e Dotti (2017).

É importante mencionarmos que no ano de 2017, o Tribunal de Contas de União (TCU) realizou auditoria materializada pelo Acórdão $\mathrm{n}^{\circ}$ 1.056/2017-P para avaliar as ações da Administração Pública Federal alinhadas ao desenvolvimento sustentável.

Logo, o objetivo deste trabalho é fazer um estudo sobre a inserção de critérios sustentáveis para redução do consumo de energia elétrica que estão presentes nos edi- tais de processos licitatórios de Universidades Públicas Federais do nordeste brasileiro relacionados a obras e serviços de engenharia para auxiliar a consolidação das LS na administração pública em coerência à Valente (2011).

Pretende-se que as considerações finais obtidas neste estudo orientem a elaboração de CPS para que essas se tornem políticas públicas e que haja respeito aos ditames da lei sem comprometer o caráter competitivo do processo licitatório.

\section{VANTAGENS E OBSTÁCULOS NAS CONTRATAÇÕES SUSTENTÁVEIS DA ADMINISTRAÇÃO PÚBLICA}

A Administração Pública ao incorporar em seus processos licitatórios critérios sustentáveis dá ao mercado um sinal a favor da sustentabilidade (OLIVEIRA; SANTOS, 2015), pois ao optar por produtos e serviços sustentáveis contribui para o aumento de fornecedores com tais produtos, estimula a capacitação dos profissionais envolvidos, melhora a eficiência dos gastos públicos e melhora o comportamento ético das empresas contratadas (ADJEI, 2010).

Tanto a realização de compras de forma compartilhada, ou seja utilizando Sistema de Registro de Preços (SRP), quanto a elaboração de editais de licitação com critérios sustentáveis estimulam a troca de experiências entre órgãos de diferentes seguimentos de atuação (SILVA; BARKI, 2012), sobretudo, durante a formação de preços que é permitida segundo a Instrução Normativa (IN) $n^{\circ} 03$ do Ministério do Planejamento, Orçamento e Gestão (MPOG) .

Nesse sentido, destacamos a recomendação feita pelo Livro 07 (INSTITUTO DE PESQUISA ECONÔMICA APLICADA, 2010, p. 294) quando ela afirma que "os padrões são parte dos instrumentos regulatórios $[\ldots]$..."

Diferente das vantagens já citadas, alguns obstáculos são relatados por Assandre (2015) que chama atenção sobre a necessidade de capacitação dos compradores públicos, a fim de que os processos licitatórios sejam feitos garantindo as melhores condi- 
ções para a Administração Pública condizentes ao menor preço possível.

Hegenberg (2012) aponta mais dois obstáculos para a promoção das CPS, quais sejam: as restrições financeiras, por entender que alguns estudos indicam que itens coerentes à sustentabilidade são mais onerosos para a Administração Pública e a estrutura organizacional que não apoia os gestores públicos.

Também podemos citar como obstáculos nas CPS a pouca capacitação dos servidores públicos dos departamentos de engenharia que elaboram termos de referência e planilhas orçamentárias para serem enviadas ao departamento de licitações (MOURA, 2013).

Em um artigo publicado por Couto e Ribeiro (2016), 35 especialistas "[...] compreendem, refutam ou validam os objetivos e estabelecem os desafios prioritários à implementação da política pública de compras sustentáveis [...]" e apontam alguns resultados seguidos do nível de consenso entre os respondentes, tais como: "A cultura organizacional das instituições públicas, ainda é resistente a questões ligadas à sustentabilidade" $(88,2 \%)$ e há "Ausência de catálogos de materiais e/ou serviços com critérios específicos para a escolha de itens sustentáveis" $(82,4 \%)$.

\section{CRITÉRIOS SUSTENTÁVEIS NAS CONTRATAÇÕES PÚBLICAS SOB A PERSPECTIVA DA LEGISLAÇÃO E DA JURISPRUDÊNCIA}

Além do caput do artigo 225 da Constituição Federal (BRASIL, 1988), a temática sustentável também consta no artigo $3^{\circ}$ da Lei 8.666/93, de 21 de junho de 1993, quando ressalta que o processo licitatório deverá promover a seleção da proposta mais vantajosa, bem como o desenvolvimento sustentável (FURTADO, 2015) e deverá ser vinculada ao instrumento convocatório.

É fato que a lei das licitações públicas traz um rol taxativo de critérios para sua fase de habilitação, que se trata da "[...] fase do procedimento em que se analisa a aptidão dos licitantes" (MELLO, 2012, p. 594) no tocante à habilitação jurídica, qualificação técnica, regularidade fiscal e trabalhista.

De todo o exposto, e certos da regulamentação como pré-requisito que garante legitimidade à inclusão de critérios sustentáveis nos editais para contratações públicas (MOURA, 2013), é necessário esclarecermos em qual fase da licitação os critérios sustentáveis devem ser incorporados.

Já que a fase de habilitação apresenta critérios taxativos, não há que se falar em exigência de critérios sustentáveis nessa fase (COSTA, 2011), nem tampouco não habilitar determinadas empresas por não apresentarem tais critérios.

Após analisar a passagem do mesmo autor, quando diz que resta ao gestor público a inclusão de critérios sustentáveis na especificação do objeto da licitação, de forma correta e motivada (COSTA, 2011), somos levados a analisar a definição de "objeto" dada por Meirelles, Aleixo e Burle Filho (2012, p. 296), bem como a definição de "edital" dada pelo mesmo autor corroborada por Mello (2012, p. 594).

Resta-nos concluir que os critérios sustentáveis devem ser postos na caracterização do objeto, e que tais critérios devem ser tornados públicos durante a licitação, logo o edital deverá conter os critérios sustentáveis definidos nos projetos de engenharia (FURTADO, 2015).

Uma observação deve ser feita nesse ponto, e refere-se ao fato de que os critérios sustentáveis inseridos no edital devem ser avaliados em todo processo licitatório, nas etapas de determinação do objeto, elaboração da planilha orçamentária, determinação dos critérios de julgamento, adjudicação do objeto e homologação do certame (FINGER, 2013).

$\mathrm{Na}$ esteira dos critérios sustentáveis, a gestão dos serviços de engenharia deve contemplá-los de forma eficiente e bem fundamentada, pois conforme é sabido no setor público não raras são as situações em que os projetos são feitos de forma incompleta, contendo cadernos de encargos incompletos, além do fato de que em muitos casos os serviços serem embasados em ver- 
bas destinadas às pressas (DAMIANI; CRUZ, 2014).

Em coerência à Oliveira e Santos (2015) está o artigo $4^{\circ}$ do Decreto $n^{\circ} 7.746$ (BRASIL, 2012b), quando dispõe que são diretrizes da sustentabilidade, entre outras de menor impacto sobre a natureza, preferência por matérias-primas e mão de obra de origem locais e utilização de recursos naturais de forma mais eficiente.

Assim podemos citar o artigo $4^{\circ} \mathrm{da}$ IN no 1 (BRASIL, 2010b) também do governo federal, quando legisla que: os projetos básicos e executivos devem ser providos de tecnologia que reduza o impacto ambiental, a utilização de equipamentos de climatização deverá ser feita apenas em locais onde for indispensável, sensores de presença devem ser instalados nos locais de pouco acesso, as lâmpadas utilizadas devem ser as fluorescentes etc.

Mesmo com a legislação já citada, a gestão socioambiental, representada pelo PLS, somente passou a ser inserida no planejamento dos órgãos e entidades da Administração Pública Federal após a IN n ${ }^{\circ} 10$ (BRASIL, 2012a) que foi tutelada pelo Acórdão no 1.056 (BRASIL, 2017b).

Durante essa auditoria algumas determinações e recomendações foram feitas (BRASIL, 2017b), dentre elas podemos destacar: "O retomar [...] as atividades da Comissão Interministerial de Sustentabilidade da Administração Pública Federal direta, autárquica e Fundacional (CISAP )"; "Concluir a revisão do Catálogo de Materiais (CATMAT) e do Catálogo de Serviços (CATSER )"; "Ampliar as ações de capacitação dos gestores relacionadas com a certificação de prédios públicos [...]"

Dessa forma, ratificamos a importância da gestão de serviços de engenharia dentro de uma instituição pública, que envolve a elaboração de projetos básicos (JUSTEN FILHO, 2014) e editais de licitação sustentáveis, para a promoção de políticas públicas alinhadas ao desenvolvimento local sustentável.

\section{CRITÉRIOS SUSTENTÁVEIS PARA EFICIÊNCIA ENERGÉTICA NAS CONTRATAÇÕES PÚBLICAS SOB A PERSPECTIVA DA ENGENHARIA}

Reis e Santos (2015) esclarecem que as práticas relacionadas à eficiência energética contribuem para o planejamento energético não obstante às dificuldades de aplicabilidade inerentes a países onde as questões socioambientais ainda estão em fase de afirmação.

A gestão de serviços de engenharia com foco nas contratações sustentáveis possibilita que as edificações sejam contempladas com certificações, tais como: Selo Azul, PROCEL e AQUA, além da internacional LEED conforme Salgado, Chatelet e Fernandez (2012), os mesmos autores chamam atenção para o fato de que a conscientização da redução do consumo energético faz parte de uma mudança cultural.

Segundo artigo $8^{\circ}$ da IN $n^{\circ} 10$ (BRASIL, 2012a), as práticas de sustentabilidade devem abranger, no mínimo: energia elétrica, água e esgoto, qualidade de vida no ambiente de trabalho, CPS, etc.

De forma mais detalhada, os editais de licitação para serviços de engenharia devem exigir alguns critérios coerentes à redução do consumo de energia elétrica voltados à sustentabilidade (ROMÉRO; REIS, 2014). Por exemplo, para aquisição de aparelhos que consomem energia elétrica (ex: refrigeradores, condicionadores de ar, moto bombas, lâmpadas, etc), um exemplo de critério é:

Só será admitida a oferta do produto $\mathrm{XXXX}$ que possua a Etiqueta Nacional de Conservação de Energia - ENCE, na(s) classe(s) XXXX, nos termos da Portaria INMETRO $\mathrm{n}^{\circ} \mathrm{XXXX}$, que aprova os Requisitos de Avaliação da Conformidade - RAC; do produto e trata da etiquetagem compulsória. (CARVALHO; FERREIRA; VILLAC, 2016).

No ano de 2015, o Ministério de Minas e Energia (MME), em parceria com o 
Centro de Pesquisas de Energia Elétrica (CEPEL), lançou o Guia para Eficiência Energética nas Edificações Públicas (CENTRO DE PESQUISAS DE ENERGIA ELÉTRICA, 2014) com o propósito de orientar gestores públicos a fím de diagnósticos energéticos e posterior implementação de medidas de eficiência energética.

São critérios sustentáveis para redução do consumo de energia elétrica em obras de engenharia: o material isolante dos sistemas de climatização das tubulações de cobre deve ser substituído periodicamente (INSTITUTO AGGEU MAGALHÃES, 2016), instalação de banco de capacitores para correção do fator de potência (INSTITUTO FEDERAL DE EDUCAÇÃO, CIÊNCIA E TECNOLOGIA DO SERTÃO PERNAMBUCANO, 2013), a instalação de sensores de presença e substituição de lâmpadas de baixo rendimento por lâmpadas de melhor rendimento com reatores eletrônicos e o estudo da envoltória (CENTRO DE PESQUISAS DE ENERGIA ELÉTRICA, 2014) e a instalação de películas nas vidraças, brises metálicos e proteção térmica sobre a laje (BRASIL, 2013b).

\section{METODOLOGIA}

As universidades públicas federais que foram pesquisadas foram as do Nordeste brasileiro por interesse dos pesquisadores e por limitações orçamentárias da pesquisa, bem como foram aquelas universidades que possuem seus respectivos PLS cadastrados na plataforma eletrônica do CISAP.

Nesta pesquisa foram feitos levantamentos de dados em documentos públicos, tais como editais de licitação e PLS. Em seguida houve a comparação dos dados coletados com as fontes bibliográficas e documentais para que algumas considerações pudessem ser feitas a fim do alcance do objetivo deste artigo.

Quanto à natureza da pesquisa, este trabalho é enquadrado na categoria teórica e aplicada porque há interesse que os resultados sejam aplicados para resolução dos problemas que ocorrem na realidade (MARCONI; LAKATOS, 2013).
Em relação ao objetivo, a pesquisa é exploratória porque possui o intuito de proporcionar uma visão geral acerca de determinado fato. Também é descritiva porque descreve as características da amostra do objeto desta pesquisa (GIL, 2016).

Quanto aos procedimentos, é bibliográfica relacionada à teoria que serve de suporte para a pesquisa e documental porque abrange dados secundários já tornados públicos (MARCONI; LAKATOS, 2013).

No tocante à forma de coleta de dados, esses foram obtidos a partir de editais de licitação que ocorreram entre os anos de 2012 e 2017 segundo parâmetros previamente estabelecidos coerentes à abordagem quantitativa. O recorte temporal se justifica porque o Decreto $\mathrm{n}^{\circ} 7.746$ foi instituído no ano de 2012 apesar da obrigatoriedade de realizar licitações de forma sustentável datar do ano da Constituição Federal.

O tamanho mínimo da amostra desta pesquisa foi determinado com base em um nível de confiança de 95\% (noventa e cinco por cento) e em um erro de 3 (três) pontos percentuais (ALENCASTRO; SILVA; LOPES, 2013). A fórmula para tamanho mínimo da amostra foi baseada naquela apresentada por Gil (2016) que é aplicada ao cálculo de amostras com população finita porque a amostra pesquisada não supera 100.000 (cem mil) elementos.

Os editais dessas universidades foram pré-selecionados no Comprasnet segundo critérios de busca baseados nos termos "construção" e "engenharia", em seguida foram numerados e sorteados aleatoriamente até que o tamanho da amostra fosse alcançado (ALENCASTRO; SILVA; LOPES, 2013) via amostragem probabilística do tipo aleatória simples (GIL, 2016).

Os editais pré-selecionados referemse à modalidade Concorrência devido ao fato de que tal modalidade confere maior qualidade ao processo licitatório porque alguns requisitos mínimos de qualificação são exigidos no início do processo segundo $\int 1^{\circ}$ do artigo 22 da Lei de licitações públicas.

A amostra contemplou 3 (três) modalidades de licitação diferentes da Concor- 
rência para a Universidade Federal da Paraíba - Tomadas de Preço no 12013 e 32013 referentes à Prefeitura Universitária e Tomada de Preço no 12016 referente ao Centro de Ciências Exatas e da Natureza - porque as Concorrências selecionadas para essa universidade não continham editais disponíveis no Comprasnet.

O método utilizado para tratamento e análise dos dados foi o indutivo porque se parte da observação de alguns fenômenos pontuais para que generalizações de toda classe sejam feitas. Também houve o implemento do método comparativo, pois houve comparações com a finalidade de verificação de similitudes e explicação de possíveis divergências entre critérios sustentáveis aplicados nos editais de licitação, nos PLS e na pesquisa documental.

O método qualitativo tem o objetivo de interpretar a realidade de critérios para redução do consumo de energia elétrica nas licitações para obras de engenharia das universidades públicas federais do Nordeste brasileiro com base nas categorias: Critérios Sustentáveis e Não Sustentáveis (CRESWELL, 2007; BARDIN, 2016).

\section{ANÁLISE E DISCUSSÃO}

As universidades pesquisadas foram: Universidade Federal do Ceará (UFC), Universidade Federal do Recôncavo da Bahia (UFRB), Universidade Federal da Paraíba (UFPB) representada pela Prefeitura Universitária e pelo Centro de Ciências Exatas e da Natureza, Universidade Federal de Sergipe (UFS) e a Universidade Federal Rural do Semi-Árido (UFERSA).

Foram definidos 55 (cinquenta e cinco) processos licitatórios na fase de préseleção (Tabela 01) e a fórmula para tamanho mínimo (GIL, 2016) definiu uma amostragem de 48 (quarenta e oito) processos licitatórios para serem analisados, restando 7 (sete) processos licitatórios que não foram analisados porque foram excluídos da amostra, conforme abaixo.

$$
n=\frac{a^{2} * p * q * N}{a^{2} \times(N-1)+\pi^{2} * n \div q}=\frac{2^{2} * 10 *(100-10) * 56}{3^{2} \div(5.5-1)+2^{2} * 10 \times(10 n-10)}=48,45
$$

Onde:

$\mathrm{n}=$ Tamanho da amostra.

$\sigma^{2}=$ Nível de confiança escolhido, expresso em número de desvio-padrão.

$\mathrm{p}=$ Percentagem com a qual o fenômeno se verifica.

$\mathrm{q}=$ Percentagem complementar $(100-\mathrm{p})$.

$\mathrm{N}=$ Tamanho da população.

$e^{2}=$ Erro máximo permitido.

Os processos licitatórios contemplam a execução de obras de engenharia, tais como a construção de salas de aula, laboratórios e estacionamentos. Durante a análise quando os critérios se encontravam repetidos entre duas licitações distintas estes critérios eram contabilizados apenas uma vez.

Tabela 01 - Processos licitatórios conforme fase de pré-seleção

\begin{tabular}{|c|c|c|c|c|c|c|c|c|c|c|c|c|c|c|}
\hline Item & Contratante & $\mathrm{N}^{\circ} / \mathrm{Ano}$ & Item & Contratante & No/Ano & Item & Contratante & $\mathrm{N}^{\circ} /$ Ano & Item & Contratante & $\mathrm{N}^{\circ} /$ Ano & Item & Contratante & N\%/Ano \\
\hline & \multirow{11}{*}{ UFC } & 312013 & 11 & \multirow{11}{*}{ UFC } & 292014 & excluído & \multirow{8}{*}{ UFRB } & 22012 & 29 & \multirow{2}{*}{ UFPB } & 32013 & 39 & \multirow{11}{*}{ UFERSA } & 52013 \\
\hline 2 & & 52013 & 12 & & 322013 & 20 & & 32012 & 30 & & 12016 & 40 & & 42013 \\
\hline 3 & & 42013 & 13 & & 312013 & 21 & & 12013 & 31 & \multirow{7}{*}{ UFS } & 122013 & 41 & & 92013 \\
\hline 4 & & 382013 & 14 & & 42016 & 22 & & 22012 & 32 & & 192012 & 42 & & 192013 \\
\hline 5 & & 442013 & excluído & & 392014 & 23 & & 82013 & 33 & & 52013 & 43 & & 202013 \\
\hline 6 & & 372013 & 15 & & 272014 & 24 & & 42013 & 34 & & 152012 & excluído & & 132013 \\
\hline 7 & & 422013 & excluído & & 12016 & 25 & & 22013 & 35 & & 32013 & 44 & & 62013 \\
\hline 8 & & 362013 & 16 & & 252014 & 26 & & 62012 & 36 & & 22016 & 45 & & 172013 \\
\hline excluído & & 452013 & 17 & & 222016 & 27 & \multirow{3}{*}{ UFPB } & 42013 & 37 & & 132013 & 46 & & 162013 \\
\hline 9 & & 502013 & 18 & & 32016 & excluído & & 32013 & excluído & \multirow{2}{*}{ UFERSA } & 182013 & 47 & & 72013 \\
\hline 10 & & 352013 & 19 & & 22016 & 28 & & 12013 & 38 & & 12013 & 48 & & 142013 \\
\hline
\end{tabular}

Fonte: Comprasnet (BRASIL, 2017a).

Nota: Dados trabalhados pelos autores. 


\subsection{Análise dos editais da UFC}

Após análise dos 19 (dezenove) editais da UFC foi possível constatar a presença de itens que contribuem para a economia de energia elétrica conforme o inciso III do artigo $4^{\circ}$ do Decreto $\mathrm{n}^{\circ} 7.746$ (BRASIL, 2012b), tais como telhas de alumínio com preenchimento de poliuretano e reatores eletrônicos com alto fator de potência (CARVALHO; FERREIRA; VILLAC, 2016, p. 48) (Tabela 02).

Tabela 02 - Critérios sustentáveis e não sustentáveis da UFC

\begin{tabular}{|c|c|c|c|}
\hline Item & Localização & Critérios S ustentáveis & N\%/Ano \\
\hline 1 & edital pg. 49 & Célula fotoelétrica $\mathrm{p}$ / lâmpada, até $1000 \mathrm{~W}$ & 312013 \\
\hline 3 & edital pg. 44 & Telha de alumínio c/miolo poliuretano, trapezoidal+trap ezoidal & 42013 \\
\hline 7 & edital pg. 44 & Impermeabilização/p roteção térmica & 422013 \\
\hline 9 & $\begin{array}{l}\text { edital pg. } 59 \\
\text { edital pg. } 60\end{array}$ & $\begin{array}{l}\text { Medidor de grandezas elétricas tip o "power meter" pm } 600 \text { schneider com display } \\
\text { Grupo gerador } 361 / 385 \mathrm{kVA} \text {, com quadro automático }\end{array}$ & 502013 \\
\hline 10 & edital pg. 49 & $\begin{array}{l}\text { Luminária de sobrepor para duas lâmpadas fluorescentes de } 32 \mathrm{~W} \text { corpo em chapa de aço fosfatizada e pintada } \\
\text { eletrostaticamente na cor branca, refletor e aletas parabólicas em alumínio anodizado de alta pureza e refletância com } \\
\text { lâmpadas e reator eletrônico }\end{array}$ & 352013 \\
\hline 14 & edital pg. 45 & $\begin{array}{l}\text { Ar Condicionado Split Inverter. Selo Procel A. (Caso não exista no mercado a classificação indicada, deverá ser } \\
\text { instalado equip amento com a melhor classificação subsequente). }\end{array}$ & 42016 \\
\hline & edital pg. 70 & Sistema de ar-condicionado exposição indireta, c/ "chillers", torres, redes hidr. & \\
\hline Item & Localização & Critérios Não S ustentáveis & N\%/Ano \\
\hline 1 & edital pg. 43 & Telhamento com telha de fibrocimento ondulada, espessura $6 \mathrm{~mm}$, incluso juntas de vedação e acessórios & 312013 \\
\hline 5 & edital pg. 58 & Lâmpada incandescente $100 \mathrm{~W}$ - fornecimento e instalacao & 442013 \\
\hline 6 & edital pg. 47 & Reator para lâmpada fluorescente $2 \times 32 \mathrm{~W}$ partida convencional & 372013 \\
\hline 9 & edital pg. 60 & Bomba centrífuga de $5 \mathrm{cv}$, inclusive mat.de sucção & 502013 \\
\hline 17 & edital pg. 58 & Split system completo c/ controle remoto - cap. 2,50 TR (fornecimento e montagem) & 222016 \\
\hline
\end{tabular}

Fonte: Comprasnet (BRASIL, 2017a).

Nota: Dados trabalhados pelos autores.

A Concorrência $n^{\circ} 502013$ indica a instalação de um medidor de grandezas elétricas (BRASIL, 2010b, Art. 4, V; UNIVERSIDADE FEDERAL DO CEARÁ, 2013; ROMÉRO; REIS, 2014), bem como a Concorrência $n^{\circ} 422013$ indica a instalação de proteção térmica conforme inciso III do artigo $4^{\circ}$ do Decreto $\mathrm{n}^{\circ} 7.746$ (BRASIL, 2012b).

Porém, também foi possível encontrarmos nos editais pesquisados exemplos de itens que não contribuem para a sustentabilidade porque suas especificações a fim de redução do consumo de energia elétrica estão em desacordo com o Guia Nacional de Licitações Sustentáveis (CARVALHO; FERREIRA; VILLAC, 2016).

Os itens apresentados na pesquisa que se mostraram não sustentáveis podem ser melhor detalhados com referências de consumo ou de eficiência energética conforme objetivo $\mathrm{n}^{\circ} \quad 07$ dos ODS
(ORGANIZAÇÃO DAS NAÇÕES
UNIDAS, 2015).

Neste tópico é importante lembrarmos que a UFC possui um Manual de Obras Públicas Sustentáveis, porém a nossa sugestão é no sentido de que as especificações técnicas que contribuirão para a redução do consumo de energia elétrica sejam inseridas na planilha orçamentária.

\subsection{Análise dos editais da UFRB}

A análise dos editais da UFRB (Tabela 03) está resumida abaixo.

Percebemos a presença de itens com exigências sustentáveis, tais como equipamentos com Selo Inmetro de eficiência (ROMÉRO; REIS, 2014; CARVALHO; FERREIRA; VILLAC, 2016), janelas com películas e programador horário de energia.

É importante pontuarmos que a presença de tais critérios em projetos de engenharia pode promover o desenvolvimento da cultura da sustentabilidade, bem 
como incentivar a redução da discrepância social e permitir o desenvolvimento sustentável (REIS; SANTOS, 2015).

Os 7 (sete) editais pesquisados da UFRB também apresentaram exemplos de descrições de itens de projeto que poderiam estar melhor detalhados no sentido de redu- ção do consumo de energia elétrica, tais como: vidros incolores, equipamentos de climatização sem especificação de eficiência de energia, bem como telha de fibrocimento segundo preconizado pelo inciso III do artigo $4^{\circ}$ do Decreto n $^{\circ} 7.746$ (BRASIL, 2012b).

Tabela 03 - Critérios sustentáveis e não sustentáveis da UFRB

\begin{tabular}{|c|c|c|c|}
\hline Item & Localização & Critérios S ustentáveis & N\%/Ano \\
\hline 20 & $\begin{array}{l}\text { item } 12.2 \text { planilha } \\
\text { item } 13.2 \text { planilha } \\
\text { item } 1.10 \text { planilha } \\
\text { item } 6.1 \text { planilha } \\
\text { item } 1.6 \text { planilha }\end{array}$ & $\begin{array}{l}\text { Impermeabilização a base de mantas contínuas de elastômetros sintéticos, calandrados e prevulcanizados, aluminizada, } \\
\text { ap licada sobre berço amortecedor, para lajes de concreto ou pre-moldadas, com espessura de } 5 \mathrm{~mm} \\
\text { Telhamento com telha Termoroof EPS } 40 \mathrm{~mm} \text {, da Dânica } \\
\text { Reator eletrônico, } 220 \mathrm{~V}, 60 \mathrm{~Hz} \text {, para } 1 \text { lâmp ada fluorescente de } 32 \mathrm{~W} \text {, fabricado conforme normas NBR-14.417 e } \\
\text { NBR-14.418, com selo de conformidade do INMETRO } \\
\text { Fornecimento e instalação de unidade condicionadora de ar, do tipo Sp lit, com capacidade unitária de } 9.000 \mathrm{BTU} / \mathrm{h} \text {, } \\
\text { c/condensador a ar remoto, de fabricação Springer Carrier ou similar, com insuflamento direto no ambiente e controle } \\
\text { remoto sem fio, com kit } \\
\text { Lâmpada fluorescente } 32 \mathrm{~W} \text {, temperatura de cor } 4.000 \mathrm{~K}\end{array}$ & 32012 \\
\hline 21 & $\begin{array}{l}\text { item de projeto } \\
\text { item de projeto } \\
\text { item } 1.26 \text { planilha }\end{array}$ & $\begin{array}{l}\text { Janelas com película } \\
\text { Cobogós e espaço aberto para ventilação permanente sob o telhado } \\
\text { Programador horário RTST } / 20 \text { com caixa em ABS, alimentação } 100 \text { A } 240 \text { VCA, display tipo lcd multi-indicativo, coel } \\
\text { ou similar - fornecimento e instalação }\end{array}$ & 12013 \\
\hline 22 & item 7.2 planilha & $\begin{array}{l}\text { Impermeabilização de laje com manta asfáltica ( calhas, lajes expostas da cobertura e pisos dos sanitarios do } 1^{\circ} \\
\text { pavimento). }\end{array}$ & 22012 \\
\hline 26 & item 4.1.1.4 planilha & $\begin{array}{l}\text { Bloco de vidro 19x19x8 cm, assentado com argamassa traço 1:3, preparo mecânico com rejuntamento em cimento } \\
\text { branco e barras de aço. }\end{array}$ & 62012 \\
\hline Item & Localização & Critérios Não S ustentáveis & N\%/Ano \\
\hline 20 & item 18.2 planilha & Vidro incolor de $4 \mathrm{~mm}$ & 32012 \\
\hline 21 & item 02357 /orse planilha & $\begin{array}{l}\text { Bomba de sucção e recalque,trifásica com chave magnética ou similar. } \\
\text { Split Hi - wall - } 9.000 \mathrm{BTU} / \mathrm{h} \text { Unidade interna - } 9.000 \mathrm{BTU} / \mathrm{h} \text { Vazão de ar } 550 / 506 / 462 \mathrm{~m} 3 / \mathrm{h} \text { com controle remoto sem } \\
\text { fio alimentação elétrica - V/60hz/0,90 kW, nível de ruído } 40 / 37 / 30 \text { unidade externa capacidade de } 60.000 \mathrm{Btu} / \mathrm{h} \\
\text { ventilador axial, escarga horiz }\end{array}$ & 12013 \\
\hline 22 & item 6.2 planilha & $\begin{array}{l}\text { Cobertura em telha de fibrocimento estrutural, perfil trap ezoidal e }=8 \mathrm{~mm} \text {, altura } 181 \mathrm{~mm} \text {, largura útil } 490 \mathrm{~mm} \text {, e largura } \\
\text { nominal de } 521 \mathrm{~mm} \text {, (canalete } 49 \text { ) completa com todos os acessórios necessários para a sua perfeita performance. }\end{array}$ & 22012 \\
\hline 26 & item 2.1 planilha & Fornecimento e Instalação e montagem de elevador sem casa de máquina e com duas paradas. & 62012 \\
\hline
\end{tabular}

Fonte: Comprasnet (BRASIL, 2017a).

Nota: Dados trabalhados pelos autores.

É importante frisarmos que a utilização de vidros incolores pode ser benéfica no sentido de reduzir o consumo de energia elétrica no tocante ao melhor aproveitamento da luz natural.

Também foi possível identificarmos ausência de medidores de energia individuais conforme previsto pelo PLS da UFRB (UNIVERSIDADE FEDERAL DO RECÔNCAVO DA BAHIA, 2014).

\subsection{Análise dos editais da UFPB}

A análise dos editais pesquisados da UFPB (Tabela 04) ficou limitada porque o Comprasnet apenas disponibiliza avisos de licitação para as Concorrências da amostragem da UFPB nesta pesquisa. Porém, foi possível fazermos a análise de uma Tomada de Preços - no 12016.

A análise indicou que houve preocupação com uma reestruturação de quadros de energia e a instalação de lâmpadas fluorescentes (UNIVERSIDADE FEDERAL DA PARAÍBA, 2013).

A inserção de critérios sustentáveis nos projetos de engenharia para redução do consumo de energia elétrica pode contribuir para que a Administração Pública reduza o consumo de energia elétrica na demanda através de políticas públicas de eficiência energética (CAUSO, 2017). 
Tabela 04 - Critérios sustentáveis e não sustentáveis da UFPB

\begin{tabular}{|c|c|l|l|}
\hline Item & Localização & \multicolumn{1}{|c|}{ Critérios Sustentáveis } & \multicolumn{1}{|c|}{$\mathbf{N}^{\circ} / \mathbf{A n o}$} \\
\hline \multirow{3}{*}{30} & planilha item 1.1 & $\begin{array}{l}\text { Reestruturação de Quadro de Força QGA, Tipo Sobrepor, com substituição de disjuntores monofásicos por } \\
\text { disjuntores trifásicos; conversão de circuitos monofásicos em circuitos trifásicos, utilizando os cabos existentes e } \\
\text { substituição do disjuntor geral de t }\end{array}$ & 12016 \\
\cline { 2 - 4 } & planilha item 1.6.1 & $\begin{array}{l}\text { luminária tipo calha, de sobrepor, com reator de partida rapida e lampada fluorescente 2x20w, completa, fornecimento } \\
\text { e instalacao }\end{array}$ & \\
\hline
\end{tabular}

Fonte: Comprasnet (BRASIL, 2017a).

Nota: Dados trabalhados pelos autores.

Nesse ponto do artigo podemos citar que no ano de 2000, o Brasil publicou a Lei $n^{\circ} 10.295 / 01$ que é a Lei de Eficiência Energética que dispõe sobre a Política Nacional de Conservação e Uso Racional de Energia, e se configura como o principal marco normativo na área de eficiência energética no Brasil (ALTOE et al., 2017, p. 286).

\subsection{Análise dos editais da UFS}

Abaixo a indicação dos 7 (sete) editais de licitação pesquisados da UFS (Tabela 05).

Após análise dos editais de licitação pesquisados da UFS, constatamos a presença de itens coerentes à economia de energia elétrica, por exemplo uso de lâmpadas do tipo Led (CARVALHO; FERREIRA; VILLAC, 2016, p. 48) e brises em alumínio.

Percebemos também o pouco detalhamento técnico sustentável nas especificações dos equipamentos de climatização e de transporte vertical (UNIVERSIDADE FEDERAL DE SERGIPE, 2013, p.28; ROMERO; REIS, 2014).

Conforme a descrição desses itens pesquisados, a sugestão é para que as especificações técnicas sejam feitas mais detalhadas a fim de que a CPS sinalize ao mercado local o objetivo de economizar energia elétrica. Porém, a licitação não deve comprometer a livre concorrência, bem como a economia de escala (OLIVEIRA; SANTOS, 2015).

Tabela05 - Critérios sustentáveis e não sustentáveis da UFS

\begin{tabular}{|c|c|c|c|}
\hline Item & Localização & Critérios S ustentáveis & $\mathbf{N} \%$ Ano \\
\hline 31 & $\begin{array}{l}\text { edital pg. } 59 \\
\text { edital pg. } 59 \\
\text { edital pg. } 60\end{array}$ & $\begin{array}{l}\text { Telhamento com telha translúcida em fibra de vidro } \\
\text { Impermeabilização com manta asfáltica } \\
\text { Brises em alumínio }\end{array}$ & 122013 \\
\hline 32 & $\begin{array}{l}\text { edital pg. } 34 \\
\text { edital pg. } 60\end{array}$ & $\begin{array}{l}\text { Bloco de isopor com função Isolante termo-acústico } \\
\text { Vidro liso fumê }\end{array}$ & 192012 \\
\hline 33 & edital pg. 125 & Sistema de climatização VRF & 52013 \\
\hline 34 & edital pg. 69 & Imp ermeabilização com manta asfáltica & 152012 \\
\hline 36 & edital pg. 42 & Lâpada tipo Led & 22016 \\
\hline 37 & edital pg. 100 & Grupo gerador completo, linha Diesel, com potência de 400 / 364 KVA & 132013 \\
\hline Item & Localização & Critérios Não Sustentáveis & $\mathbf{N} \%$ Ano \\
\hline 31 & $\begin{array}{l}\text { edital pg. } 64 \\
\text { edital pg. } 66 \\
\text { edital pg. } 69\end{array}$ & $\begin{array}{l}\text { Telhamento com telha de fibrocimento ondulada } \\
\text { Vidro temperado liso } \\
\text { Luminária com lâmpada fluorescente com reator }\end{array}$ & 122013 \\
\hline 34 & $\begin{array}{l}\text { edital pg. } 83 \\
\text { edital pg. } 83\end{array}$ & $\begin{array}{l}\text { Split } 60.000 \mathrm{BTU} / \mathrm{h} \\
\text { Plataforma elevatória para pessoas com mobilidade reduzida }\end{array}$ & 152012 \\
\hline
\end{tabular}

Fonte: Comprasnet (BRASIL, 2017a).

Nota: Dados trabalhados pelos autores.

Neste ponto do artigo é mister pontuarmos que em determinados casos o gestor público pode se deparar com situações em que a inclusão de especificações técnicas alinhadas à sustentabilidade pode ficar com- prometida por limitações de disponibilização do mercado local, ou até mesmo por limitações da estrutura organizacional (HEGENBERG, 2012). 


\subsection{Análise dos editais da UFERSA}

A análise dos itens dos editais de licitação pesquisados da UFERSA (Tabela 06) demonstrou a presença de vidros lisos aplicados com películas, bem como reatores eletrônicos e impermeabilização de cobertas para fins de redução do consumo de energia elétrica (BRASIL, 2012b, Art. 4º, III; UNIVERSIDADE FEDERAL RURAL DO SEMI-ÁRIDO, 2013).

Também percebemos a presença de vidros lisos sem película na Concorrência $n^{\circ}$ 052013, bem como a presença de telha de fibrocimento com ausência de proteção térmica em desacordo com o Guia Nacional de Licitações Sustentáveis (CARVALHO; FERREIRA; VILLAC, 2016).

Em nenhum desses dados analisados foi possível constatarmos a presença de me- didores individualizados de energia (UNIVERSIDADE FEDERAL RURAL DO SEMI-ÁRIDO, 2013).

É importante citarmos que o detalhamento e a procura por itens ambientalmente corretos no CATMAT e no CATSER podem ser insatisfatórios porque um dos obstáculos para a CPS é a ausência de catálogos de materiais para itens sustentáveis (COUTO; RIBEIRO, 2016).

Porém, a IN no 03 do MPOG orienta sobre a realização de pesquisa de preços para aquisição de bens e contratação de serviços em geral e que tal etapa é importante para que os editais das CPS se tornem padrões de consulta durante a troca de experiências entre diferentes órgãos da Administração Pública (SILVA; BARKI, 2012).

Tabela 06 - Critérios sustentáveis e não sustentáveis da UFERSA

\begin{tabular}{|c|c|c|c|}
\hline Itens & Localização & Critérios Sustentáveis & $\mathbf{N}^{\circ} /$ Ano \\
\hline 38 & $\begin{array}{l}\text { planilha item 8.3.1 } \\
\text { planilha item } 14.1 .1\end{array}$ & $\begin{array}{l}\text { Impermeabilização de coberturas planas com manta asfática } 3 \mathrm{~mm} \text {, protegida com filme de alumínio gofrado 0,8mm } \\
\text { Luminária de embutir, com corpo em chapa de aço fosfatizada e pintada eletrostaticamente, refletor e aletas parabólicas } \\
\text { em alumínio anodizado de alta pureza e refletância, c/ duas lâmpadas fluorescentes tubular de } 40 \mathrm{~W}\end{array}$ & 12013 \\
\hline 39 & $\begin{array}{l}\text { memorial pg. } 71 \\
\text { planilha item } 8.7\end{array}$ & $\begin{array}{l}\text { Reator eletrônico com alto fator de potência }(0,95) \text { para lâmpadas fluorescentes tubulares de } 18 \mathrm{~W} \text { e } 36 \mathrm{~W} \\
\text { Luminária de embutir, com corpo em chapa de aço fosfatizada e pintada eletrostaticamente, refletor e aletas parabólicas } \\
\text { em alumínio anodizado de alta pureza e refletância, com duas lâmpadas fluorescente tubular de } 32 \mathrm{w} \text {. Fornecimento e } \\
\text { instalação. }\end{array}$ & 52013 \\
\hline 46 & $\begin{array}{l}\text { planilha item } 7.15 \\
\text { planilha item } 7.16\end{array}$ & $\begin{array}{l}\text { Fornecimento e instalação de Vidro liso } 6 \mathrm{~mm} \text { para janelas e portas, inclusive baguetes e borrachas de vedação. } \\
\text { Fornecimento e instalação de película grafite para vidros das janelas e portas }\end{array}$ & 162013 \\
\hline Itens & Localização & Critérios Não S ustentáveis & $\mathbf{N}^{\circ} /$ Ano \\
\hline 38 & planilha item 7.1 & Telhamento com telha de fibrocimento ondulada & 12013 \\
\hline 39 & planilha item 13.4 & Vidro liso incolor espessura $=6 \mathrm{~mm}$, fixado com borracha de vedação (Instalado). & 52013 \\
\hline
\end{tabular}

Fonte: Comprasnet (BRASIL, 2017a).

Nota: Dados trabalhados pelos autores.

Ou seja, os itens que se mostraram com pouco detalhamento coerentemente à redução do consumo de energia elétrica podem ser utilizados como referência em projetos futuros, segundo a IN $n^{\circ} 03$ do MPOG, após devidas atualizações conforme, por exemplo, o Guia Nacional de Licitações Sustentáveis (CARVALHO; FERREIRA; VILLAC, 2016).

Também é mister pontuarmos que na ausência de itens técnicos de engenharia o gestor público pode sugerir a inclusão desses nas tabelas oficiais de pesquisa de preços ou no CATMAT e no CATSER.

\section{CONSIDERAÇÕES FINAIS.}

Após a análise dos critérios utilizados pelas universidades pesquisadas, podemos destacar que algumas especificações técnicas contribuem para que o projeto de engenharia contenha itens sustentáveis no tocante à redução do consumo de energia elétrica. Porém, outros itens precisam ter suas redações mais detalhadas para fins do efetivo alcance das CPS.

Nessa esteira, o item $\mathrm{n}^{\circ} 14$ da UFC possui uma especificação de equipamento de climatização com determinada eficiência de energia elétrica (BRASIL, 2013a). 
Os critérios sustentáveis verificados na pesquisa da UFRB também demonstram que há presença de itens que auxiliam na redução do consumo de energia elétrica, tais como lâmpadas fluorescentes e reatores eletrônicos.

Janelas com película e laje com proteção térmica também auxiliam na redução do consumo de energia elétrica conforme inciso III do artigo $4^{\circ}$ do Decreto $\mathrm{n}^{\circ} 7.746$ (BRASIL, 2012b). A UFRB também utilizou blocos de vidro na Concorrência 62012 que podem ser ambientalmente corretos para fins de melhor aproveitamento da iluminação natural.

A UFPB contribui neste estudo porque demonstrou preocupação com a reestruturação dos sistemas elétricos através da Tomada de Preços no 12016 coerentemente ao seu PLS (UNIVERSIDADE FEDERAL DA PARAÍBA, 2013). Tal reestruturação pode ser feita a fim de que o contrato de fornecimento de energia elétrica seja revisto (BRASIL, 2013b) e consequentemente haverá maior economia de energia elétrica sem comprometer as necessidades humanas.

A pesquisa dos critérios sustentáveis da UFS indicou a utilização de blocos de isopor com função de isolante térmico que contribuem para redução do consumo de energia elétrica porque reduzem a carga térmica sobre o sistema de climatização.

É importante relatarmos que a utilização de telhas com preenchimento de poliuretano, a princípio, pode ser substituída por telhas de fibrocimento desde que haja instalação de mantas térmicas sob as telhas conforme PLS da UFERSA (UNIVERSIDADE FEDERAL RURAL DO SEMIÁRIDO, 2013; ROMÉRO; REIS, 2014).

A utilização de sistema de climatização por expansão indireta no item $\mathrm{n}^{\circ} 15 \mathrm{da}$ Concorrência 272014 da UFC, bem como a utilização de sistema de climatização do tipo VRF no item n ${ }^{\circ} 33$ da Concorrência 052013 da UFS demonstram que tais universidades estão coerentes com o Guia para Eficiência Energética nas Edificações Públicas do CEPEL (CENTRO DE PESQUISAS DE ENERGIA ELÉTRICA, 2014, p. 45).
Desta forma, os critérios utilizados em projetos de engenharia contribuirão para a construção de políticas públicas alinhadas às LS (REIS; SANTOS, 2015) como por exemplo o Plano Nacional de Energia 2030 (PNE) (EMPRESA DE PESQUISA ENERGÉTICA, 2007) elaborado pelo MME em parceria com a EPE, bem como no ano de 2010 elaborou o Plano Nacional de Eficiência Energética (PNEf) (BRASIL, 2010a; GOMES, 2017).

Ao lado dos critérios sustentáveis que contribuem para a redução do consumo de energia elétrica, a pesquisa também demonstrou que os editais que compuseram a amostragem possuem itens que necessitariam de especificações técnicas mais detalhadas no sentido de contribuir para a consolidação das LS via redução do consumo de energia elétrica conforme, por exemplo, o Guia para Eficiência Energética nas Edificações Públicas do CEPEL (CENTRO DE PESQUISAS DE ENERGIA ELÉTRICA, 2014) e o Guia Nacional de Licitações Sustentáveis (CARVALHO; FERREIRA; VILLAC, 2016).

Quando visualizamos a presença de itens nas planilhas orçamentárias das obras de engenharia ou nos projetos básicos com pouco detalhamento referente à eficiência energética da edificação, não obstante previsão legal para inclusão de tais critérios, lembramos dos obstáculos citados por Hegenberg (2012) e complementados por Assandre (2015).

Aqui é necessário pontuarmos que após finalizada a Licitação a obediência às especificações técnicas cabe à fiscalização do contrato segundo inciso IV do artigo $13 \mathrm{da}$ Lei 8.666/93 (BRASIL, 1993) e que a inclusão de critérios sustentáveis após iniciada a obra é uma atividade que pode comprometer os prazos e relações administrativas entre contratante e contratada.

Durante a pesquisa também houve a constatação de que alguns itens disponibilizados pelas tabelas oficiais precisam conter mais detalhamentos técnicos no que tange critérios sustentáveis (COUTO; RIBEIRO, 2016). A IN n ${ }^{\circ} 03$ do MPOG discorre sobre a pesquisa de preços no mercado local para 
facilitar a inserção de itens sustentáveis na licitação de forma a substituir itens das tabelas oficiais.

Utilizar pesquisa de preços e não utilizar itens das tabelas oficiais, muitas vezes não sustentáveis, vai de encontro à cultura organizacional da instituição pública (COUTO; RIBEIRO, 2016), bem como necessita de segurança jurídica que só será alcançada via capacitação dos servidores públicos (KORKMAZ, 2010; ASSANDRE, 2015).
Como última consideração deste artigo podemos citar que a elaboração dos PLS por parte das universidades pesquisadas demonstra maturidade dos gestores públicos no sentido de diminuir a presença de itens com deficiência de especificação técnica alinhados à redução do consumo de energia elétrica e desta forma contribuir para a consolidação das LS dentro do contexto das políticas públicas de eficiência energética na administração pública.

\title{
MANAGEMENT OF ENGINEERING WORK IN FEDERAL PUBLIC UNIVERSI- TIES OF THE BRAZILIAN NORTHEAST: A study for sustainable public hirings
}

\begin{abstract}
Aiming to contribute to the consolidation of Sustainable Biddings in public administration in line with the Sustainable Development and the statutory requirements, this article investigated criteria for reducing electrical energy consumption in bidding processes for engineering works used by Federal Public Universities of the Brazilian Northeast regarding the Sustainable Public Hirings. The theoretical methodology was used and applied to the exploratory and descriptive nature in terms of the objective and bibliographic and documental about the procedures. The sources for collection data were the federal government procurement portal (Comprasnet) and a bibliographic and documentary research that involved the Logistics Management Plans of Sustainable Development of the studied universities. The research approach is quali-quanti because it involved data processing based on previously defined categories, as well as data collection according to parameters previously established. The final considerations show that universities need to overcome some obstacles, such as lack of public managers training and organizational culture so that their Sustainable Public Hirings become publics policies in line with the Sustainable Development.
\end{abstract}

\section{Keywords}

Sustainable public birings. Sustainable development. Federal Public Universities of the Brazilian Northeast. Publics policies. Engineering Works.

Artigo recebido em 31/01/2018 e aceito para publicação em 28/07/2018

\section{REFERÊNCIAS}

ADJEI, A. B. Sustainable public procurement: a new approach to good governance. In: INTERNATIONAL PUBLIC PROCUREMENT CONFERENCE, 4., 2010, Seoul, South Korea. IPPC 4 Proceedings... Seoul, South Korea, 2010. Disponível em:

<http://www.ippa.org/images/PROCEED INGS/IPPC4/07GreenProcurement/Paper 7-10.pdf>. Acesso em: 11 set. 2017.

ALENCASTRO, M. A. C.; SILVA. E. V.; LOPES. A. M. D' A. Contratações sustentáveis na administração pública brasileira: a experiência do Poder Executivo federal.
RAP - Revista de Administração Pública, v. 48, n .01, p. 207-235. 2014. Disponível em:

$<$ http://bibliotecadigital.fgv.br/ojs/index.p $\mathrm{hp} / \mathrm{rap} /$ article/view/16072/14899>. Acesso em: 22 ago. 2017.

ALTOE, L. Et al. Políticas públicas de incentivo à eficiência energética. Estudos avançados, São Paulo - SP, v. 31, n. 89, p. 285-297, 2017. Disponível em:

$<$ https://www.revistas.usp.br/eav/article/vi ew/132432 >. Acesso em: 05 abr. 2018.

ASSANDRE, J. A. Barreiras e potenciais facilitadores para implantação de compras sustentáveis na Universidade Fede- 
ral de São Carlos. 91 f. Dissertação (Mestrado) - Programa de Pós-graduação em Gestões de Organizações e Sistemas Públicos. Universidade Federal de São Carlos UFSCar. São Carlos. 2015.

BARDIN, L. Análise de conteúdo. São Paulo: Edições 70, 2016.

BLIACHERIS, M. W. Licitações sustentáveis: política pública. In: SANTOS, M. G.; VILLAC, T. (Coord.). Licitações e contratações públicas sustentáveis. 2. ed. Belo Horizonte: Fórum, 2015. p. 141-156.

BRASIL. Instituto Nacional de Metrologia, Qualidade e Tecnologia (INMETRO). Portaria. MDIC N. ${ }^{\circ}$ 410, de 16 de agosto de 2013a. Aprova a revisão das classes de eficiência energética e o formato da Etiqueta Nacional de Conservação de Energia - ENCE para condicionadores de ar.

BRASIL. Ministério da Fazenda. Plano de Gestão de Logística Sustentável. Versão 1.0 - agosto de 2013b. Brasília. Disponível em:

$<$ http://cpsustentaveis.planejamento.gov.br />. Acesso em: 26 set. 2017.

BRASIL. Ministério de Minas e Energia. Plano nacional de eficiência energética. Brasília-DF, 2010a. Disponível em: $<$ http://www.mme.gov.br/web/guest/publ icacoes-e-indicadores $>$. Acesso em: 03 abr. 2013.

BRASIL. Ministério do Meio Ambiente. Agenda ambiental na administração pública - A3P. Brasília. 5. ed. 2009. Disponível em: <http://www.mma.gov.br/>. Acesso em: 11 set. 2017.

BRASIL. Ministério do Planejamento, Orçamento e Gestão. Estatísticas Gerais das Compras Governamentais. Brasília. 2017a. Disponível em: $<$ https://www.comprasgovernamentais.gov. br>. Acesso em: 25 out. 2017.
BRASIL. Ministério do Planejamento, Orçamento e Gestão. Instrução Normativa no 01, de 19 de janeiro de 2010b. Dispõe sobre os critérios de sustentabilidade ambiental na aquisição de bens, contratação de serviços. DOU Seção I, n. 13, p. 40 de 20 de janeiro de 2010. Disponível em: $<$ http://portal.in.gov.br>. Acesso em: 15 set. 2017.

BRASIL. Ministério do Planejamento, Orçamento e Gestão. Instrução Normativa no 10 , de 12 de novembro de 2012a. Estabelece regras para elaboração dos Planos de Gestão de Logística Sustentável e dá outras providências. DOU Seção I, n. 220, p. 113 de 14 de novembro de 2012. Disponível em: $<$ http://portal.in.gov.br>. Acesso em: 22 set. 2017.

BRASIL. Presidência da República. Constituição da República Federativa do Brasil. Brasília, DF: Senado, 1988. Disponível em: $<$ http://www.planalto.gov.br/ccivil_03/con stituicao/constituicao.htm>. Acesso em: 10 set. 2017.

BRASIL. Presidência da República. Decreto n. 7.746, de 05 de junho de 2012b. Dispõe sobre a regulamentação do art. $3^{\circ}$ da Lei no 8.666, de 21 de junho de 1993, para estabelecer critérios, práticas e diretrizes gerais para a promoção do desenvolvimento nacional sustentável por meio das contratações realizadas pela administração pública federal direta, autárquica e fundacional e pelas empresas estatais dependentes, e institui a Comissão Interministerial de Sustentabilidade na Administração Pública - CISAP. Disponível em:

<http://www.planalto.gov.br/ccivil_03/_At o2011-2014/2012/Decreto/D7746.htm>. Acesso em: 11 set. 2017.

BRASIL. Tribunal de Contas da União. Acórdão 1.056/2017b - Plenário. Relator: Ministro André Luis de Carvalho. Sessão ordinária em 24/05/2017. 2017.

CARVALHO, F. G.; FERREIRA, M. A. S. O.; VILLAC, T. Guia Nacional de Licita- 
ções Sustentáveis. Brasília: AGU, 2016.

Disponível em:

$<$ http://www.agu.gov.br/page/content/det

ail/id_conteudo/400787>. Acesso em: 18 set. 2017.

CAUSO, A. F. T. Mecanismos políticos para promoção da eficiência energética $e$ geração renovável em edificações: um estudo de caso da Alemanha e aplicações para o Brasil. 199f. Dissertação (Mestrado). Programa de Pós-Graduação em Planejamento de Sistemas Energéticos. Universidade de Brasília, Brasília - DF, 2017.

CENTRO DE PESQUISAS DE ENERGIA ELÉTRICA (CEPEL). Guia para eficiência energética nas edificações públicas. Versão 1.0 2014. Coordenador Ministério de Minas e Energia - MME - Rio de Janeiro: CEPEL, 2014. 229 p. Disponível em: <http://www.mme.gov.br/>. Acesso em: 23 set. 2017

CONFERÊNCIA DAS NAÇÕES UNIDAS SOBRE MEIO AMBIENTE E DESENVOLVIMENTO (CNUMAD). Agenda 21. Brasília: Senado Federal/SSET, 1996. $591 \mathrm{p}$.

COSTA, C. E. L. As Licitações Sustentáveis na ótica do Controle Externo. 2011. Artigo (Especialização em Auditoria e Controle Governamental) - Instituto Serzedello Corrêa /Tribunal de Contas da União, Brasília -DF, 2011.

COUTO, H. L. G.; RIBEIRO, F. L. Objetivos e desafios da política de compras públicas sustentáveis no Brasil: a opinião dos especialistas RAP - Revista de Administração Pública, Rio de Janeiro, v. 50, n. 2, p. 331-343, 2016. Disponível em: $<$ http://bibliotecadigital.fgv.br/ojs/index.p hp/rap/index >. Acesso em: 18 set. 2017.

CRESWELL, J. W. Projeto de pesquisa: métodos qualitativo, quantitativo e misto. 2. ed. Porto Alegre: Artmed, 2007. 248p.
DAMIANI, R. M.; CRUZ, L. S. Lei 8666/93: Influência da contratação pelo menor preço na qualidade dos produtos entregues. Revista interfaces científicas, Aracaju, v. 3, n. 1, p. 63 - 72, 2014. Disponível em:

$<$ https://periodicos.set.edu.br/index.php/d ireito/index>. Acesso em: 8 nov. 2017.

DI PIETRO, M. S. Z. Direito administrativo. 29. ed. Rio de Janeiro, Forense, 2016.

EMPRESA DE PESQUISA ENERGÉTICA (EPE). Plano Nacional de Energia 2030. EPE, 2007. Disponível em: $<$ http://www.epe.gov.br/default.aspx>. Acesso em: 05 abr. 2018.

FINGER, A. C. Licitações sustentáveis como instrumento de política pública na concretização do direito fundamental ao meio ambiente sadio e ecologicamente equilibrado. A\&C - Revista de Direito Administrativo \& Constitucional, Belo Horizonte, v.13, n. 51, p. 121-153, jan./mar. 2013. Disponível em:

$<$ http://www.revistaaec.com/index.php/re vistaaec/index >. Acesso em: 16 set. 2017.

FURTADO, L. R. Curso de licitações e contratos administrativos. 6. ed. rev. atual. e ampl. Belo Horizonte: Fórum, 2015

GIL, A. C. Métodos e técnicas de pesquisa social. 6. ed. São Paulo, Atlas, 2016.

GOMES, A. F. Eficiência energética em edificações públicas do poder executivo federal: oportunidades e desafios no contexto do programa brasileiro de etiquetagem (PBE - edifica). 222f. Dissertação (Mestrado). Programa de Pós-Graduação da Faculdade de Arquitetura e Urbanismo. Universidade de Brasília, Brasília - DF, 2017.

HEGENBERG, J. T. As compras públicas sustentáveis no Brasil: um estudo nas universidades federais. $255 \mathrm{f}$. Dissertação (Mestrado) - Programa de Pós-graduação em Planejamento e Governança Pública - Uni- 
versidade Tecnológica Federal do Paraná, Curitiba, 2013.

INSTITUTO AGGEU MAGALHÃES (IAM/FIOCRUZ PERNAMBUCO). Plano de Gestão de Logística Sustentável. Pernambuco. 2016. Disponível em: $<$ http://cpsustentaveis.planejamento.gov.br />. Acesso em: 26 set. 2017.

INSTITUTO DE PESQUISA ECONÔMICA APLICADA (IPEA). Sustentabilidade ambiental no Brasil: biodiversidade, economia e bem-estar humano. 2010. Brasília. 640p.

INSTITUTO FEDERAL DE EDUCAÇÃO, CIÊNCIA E TECNOLOGIA DO SERTÃO PERNAMBUCANO (IF SERTÃO-PE). Plano de Logística Sustentável. Petrolina-PE. Biênio 2013-2014. 2013. Disponível em: <http://www.ifsertaope.edu.br/>. Acesso em: 26 set. 2017.

JUSTEN FILHO, M. Comentários à lei de licitações e contratos administrativos. 16. ed. São Paulo: RT, 2014.

KORKMAZ, A. Benefits and obstacles of environmental, social and sustainable procurement. In: INTERNATIONAL PUBLIC PROCUREMENT CONFERENCE, 4., 2010, Seoul, South Korea. IPPC 4 Proceedings... Seoul, South Korea, 2010. Disponível em:

$<$ http://www.ippa.org/images/PROCEED INGS/IPPC4/07GreenProcurement/Paper 7-2.pdf>. Acesso em: 11 set. 2017.

MARCONI, M. A.; LAKATOS, E. M. Técnicas de pesquisa: planejamento e execução de pesquisas, amostragens e técnicas de pesquisa, elaboração, análise e interpretação de dados. 7. ed. São Paulo: Atlas, 2013.

MEIRELLES, H. L.; ALEIXO, D. B.; BURLE FILHO, J. E. Direito administrativo brasileiro. 38. ed. São Paulo, Malheiros, 2012.
MELLO, C. A. B. Curso de Direito Administrativo. 29. ed. São Paulo, Malheiros, 2012.

MOURA, A. M. M. As compras públicas sustentáveis e sua evolução no Brasil. Boletim regional, urbano e ambiental, n. 7, p. 23-33, jan./ jun. 2013. Disponível em: $<$ http://www.ipea.gov.br/portal/index.php ?op-

tion $=$ com_content\&view $=$ article\&id $=20697$ \&Itemid $=7$ > . Acesso em: 17 jul. 2018.

OLIVEIRA, B. C. S. C. M.; SANTOS, L. M. L. Compras públicas como política para o desenvolvimento sustentável. Adminstração Pública, Rio de Janeiro, v. 49, n. 1, p. 189-206, fev. 2015. Disponível em: $<$ http://bibliotecadigital.fgv.br/ojs/index.p hp/rap/index >. Acesso em: 12 set. 2017.

ORGANIZAÇÃO DAS NAÇÕES UNIDAS (ONU). Programa das Nações Unidas para o Desenvolvimento. Transformando Nosso Mundo: a Agenda 2030 para o Desenvolvimento Sustentável. 2015. Disponível em:

$<$ http://www.br.undp.org/content/brazil/p t/home/post-2015/>. Acesso em: 07 nov. 2017.

PEREIRA JÚNIOR, J. T.; DOTTTI, M. R. Políticas públicas nas licitações e contratações administrativas. 3. ed. Belo Horizonte: Fórum, 2017.

REIS, L. B.; SANTOS, E. C. Energia elétrica e sustentabilidade: aspectos tecnológicos, socioambientais e legais. São Paulo. 2. ed. Manole, 2015.

ROMÉRO, M. A.; REIS, L. B. Eficiência energética em edifícios. São Paulo. Manole, 2014.

ROSSET, A. C. S. Compras públicas sustentáveis: um estudo dos critérios de sustentabilidade utilizados nas contratações da Empresa Brasileira de Infraestrutura Aeroportuária - INFRAERO. 134 f. Dissertação (Mestrado Profissional em Administração 
Pública) - Universidade Federal de Alagoas. Faculdade de Economia, Administração e Contabilidade, Maceió, 2017.

SALGADO, M. S. CHATELET, A.; FERNANDEZ, P. Produção de edificações sustentáveis: desafios e alternativas. Revista ambiente construído. Porto Alegre. v.12, n.4, p.81-99. 2012. Disponível em: $<$ http://www.seer.ufrgs.br/index.php/ambi enteconstruido/index $>$. Acesso em: 08 nov. 2017.

SILVA, R. C.; BARKI, T. V. P. Compras públicas compartilhadas: a prática das licitações sustentáveis. Revista do Serviço Público, Brasília. v. 63, n.2, p.157-175. 2012. Disponível em:

$<$ https://revista.enap.gov.br/index.php/RS P/index >. Acesso em: 08 nov. 2017.

UNIVERSIDADE FEDERAL DA PARAIBA (UFPB). Plano de Logística Sustentável. João Pessoa, 2013. Disponível em: $<$ http://www.ufpb.br/>. Acesso em: 25 ago. 2017.

UNIVERSIDADE FEDERAL DE SERGIPE (UFS). Plano de Logística Sustentável. Aracaju, 2013. Disponível em: < http://www.ufs.br/>. Acesso em: 25 ago. 2017.

UNIVERSIDADE FEDERAL DO CEARÁ (UFC). Plano de Logística Sustentável. Fortaleza, 2013. Disponível em:

$<$ http://www.ufc.br/>. Acesso em: 25 ago. 2017.

UNIVERSIDADE FEDERAL DO RECÔNCAVO DA BAHIA (UFRB). Plano de Logística Sustentável. Cruz das Almas - BA, 2014. Disponível em:

$<$ https://ufrb.edu.br/portal/>. Acesso em: 25 ago. 2017.

UNIVERSIDADE FEDERAL RURAL DO SEMI-ÁRIDO (UFERSA). Plano de Logística Sustentável. Mossoró, 2013. Disponível em: <https://ufersa.edu.br/>. Acesso em: 25 ago. 2017.

VALENTE, M. A. L. Marco legal das licitações e compras sustentáveis na Administração Pública. 2011. Disponível em: <http://www2.camara.leg.br/acamara/documentos-e-pesquisa/estudos-enotas-tecnicas/areas-daconle/tema1/2011_1723.pdf>. Acesso em: 17 jul. 2018. 